Published by Al-Nahrain College of Medicine P-ISSN 1681-6579

E-ISSN 2224-4719

Email: iraqijms@colmed-alnahrain.edu.iq

http://www.colmed-alnahrain.edu.iq

http://www.iraqijms.net

\title{
Cervical Cancer Screening in Developing Countries
}

\author{
Ban J. Qasim PhD \\ Dept. of Pathology and Forensic Medicine, College of Medicine, Al-Nahrain University, Baghdad, Iraq
}

\begin{abstract}
Cervical cancer (CC) represents the most common cancer among women in developing countries. Present confirmation suggests that human papillomavirus (HPV) testing is more efficient than cytology for CC screening. Even if implementing a high-quality cytology programme in these countries is probable, it would only be fairly effective. This is because the presently used Pap test misses approximately $50 \%$ of high-grade precursor lesions and cancers with a single screening.

Several screening alternatives have been planned for areas with incomplete resources. Amid these, visual inspection with acetic acid (VIA) includes the application to the cervix of $5 \%$ diluted acetic acid (vinegar), making the dysplastic epithelium turn white (acetowhitening). Screening with HPV testing and VIA have been verified to be effective and potentially cost-effective in low-resource settings, allowing for fewer follow-up visits (e.g., screen-and-treat approaches) and, in the case of HPV testing, automated processing of laboratory specimens that reduces resource and quality control necessities
\end{abstract}

Keywords Cervical cancer, screening, cytology, human papillomavirus testing, visual inspection with acetic acid Citation Ban J. Qasim. Cervical cancer screening in developing countries. Iraqi JMS. 2017; Vol. 15(1): 1-3. doi: 10.22578/JMMS.15.1.1

List of abbreviation: $C C=$ Cervical cancer, $\mathrm{HPV}=$ human papillomavirus, VIA = Visual inspection with acetic acid

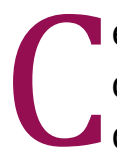
ervical cancer (CC) represents the most common cancer among women in developing countries, principally because of the failure either to start or continue successful cervical-cancer screening programs. This potentially preventable and curable cancer continues to cause high mortality among relatively young women living in low-resource countries (1). The main obstacles inbuilt to these countries are poverty and a deficient healthcare infrastructures and trained practitioners. With the availability of novel technologies, researchers have attempted to discover new strategies that are modified to low- and middle-income countries to encourage early diagnosis of cervical pathology. Present confirmation suggests that human papillomavirus (HPV) testing is more efficient than cytology for CC screening (2).

The implementation of health care measures to prevent cervical cancer reflects the priority of women (especially middle aged women) in a society, as well as the civilization and progress of a country. However, this measure has not been employed by developing countries, and the goal to screen $\mathrm{CC}$ for middle aged women has not been realized. This is probably attributed to the imbalance of health care resources in developing countries; limited medical resources are used in a small population (3).

Even though new studies hold up the possible promise of an effective vaccine against selected high-risk types of HPV, the vaccine is not up till now commercially accessible $(4,5)$. Given that first-generation vaccines will target 
young adolescents, it will require several decades to settle on the effect of these vaccines on the rate of death from cervical cancer. As current vaccines target only two types of oncogenic HPV, a combination of screening and vaccination will most likely be necessary. Thus, appropriate accomplishment of a cost-effective screening plan for use in developing countries is chiefly critical ${ }^{(6)}$.

A cytology-based (Pap test) screening program requires repeat testing and visits to recognize women who require treatment. In addition, a cytopathologist, a colposcopy specialist and a pathologist should also be concerned. To promise the success of a screening program, training and ongoing education are vital (7). Preceding knowledge has shown no decline in the incidence and/or mortality of CC and this is perhaps because of low-quality cytology smears ${ }^{(8)}$. Furthermore, even if implementing a high-quality cytology program in these countries is probable, it would only be fairly effective. This is because the presently used Pap test misses approximately $50 \%$ of highgrade precursor lesions and cancers with a single screening. As well, in low-resource settings, women would probably only be screened once or twice in their lifetime $(2,9)$.

Several screening alternatives have been planned for areas with incomplete resources. amid these, visual inspection with acetic acid (VIA) includes the application to the cervix of $5 \%$ diluted acetic acid (vinegar), making the dysplastic epithelium turn white (acetowhitening). The key advantages of this technique are that unlike conventional cytology, it is of little cost, uncomplicated to carry out and does not need specialized laboratory. The outcomes of the test are obtained more or less without delay facilitating same-day screen and management. However, VIA is controversial because of concerns over its reproducibility and accuracy ${ }^{(10)}$.

HPV testing presently has restricted use in lowincome countries. It demands laboratory infrastructure, skilled technicians, and storage services. Still, HPV testing provides a reproducible profile of women who are at high risk of developing precancerous or cancerous lesions. When used unaccompanied, or in combination with VIA, HPV DNA testing has shown great promise ${ }^{(11)}$.

Screening with HPV testing and VIA have been verified to be effective (12-14) and potentially cost-effective (6) in low-resource settings, allowing for fewer follow-up visits (e.g., screenand-treat approaches) and, in the case of HPV testing, automated processing of laboratory specimens that reduces resource and quality control necessities (15). Besides, the World Health Organization has newly recommended the use of HPV testing or VIA for cervical cancer screening in those regions and countries that have not previously established a successful, high-coverage Pap-based program (16).

Management options differ for women who test positive for HPV. In low resource settings where colposcopy and biopsy may not be on hand, conducting VIA after a positive HPV test can help decide if precancerous lesions are present on the cervix and if cryotherapy treatment is fitting. In some settings, even if the woman does not have a visibly noticeable lesion, cryotherapy has been performed on the whole cervical transformation zone particularly if the woman is unlikely to come back for follow-up care ${ }^{(17)}$.

\section{References}

1. Wright TC Jr, Kuhn L. Alternative approaches to cervical cancer screening for developing countries. Best Pract Res Clin Obstet Gynaecol. 2012; 26: 197208. doi: 10.1016/j.bpobgyn.2011.11.004.

2. Catarino R, Petignat $P$, Dongui $G$, et al. Cervical cancer screening in developing countries at a crossroad: Emerging technologies and policy choices. World J Clin Oncol. 2015; 6: 281-90. doi: 10.5306/wjco.v6.i6.281.

3. Qiao YL. Perspective of cervical cancer prevention and control in developing countries and areas. Chin J Cancer. 2010; 29: 1-3.

4. Koutsky LA, Ault KA, Wheeler CM, et al. A controlled trial of a human papillomavirus type 16 vaccine. $\mathrm{N}$ Engl J Med. 2002; 347: 1645-51. doi: 10.1056/NEJMoa020586.

5. Harper DM, Franco EL, Wheeler C, et al. Efficacy of a bivalent $L 1$ virus-like particle vaccine in prevention of infection with human papillomavirus type 16 and 18 
in young women: a randomised control trial. Lancet. 2004; 364: 1757-65. doi: 10.1016/S01406736(04)17398-4.

6. Goldie SJ, Gaffikin L, Goldhaber-Fiebert JD, et al. Cost-effectiveness of cervical-cancer screening in five developing countries. N Engl J Med. 2005; 353: 215868. DOI: 10.1056/NEJMsa044278.

7. Denny L, Quinn M, Sankaranarayanan R. Chapter 8: Screening for cervical cancer in developing countries. Vaccine. 2006; 24 Suppl 3: S3/71-S3/77. doi: 10.1016/j.vaccine.2006.05.121.

8. Sankaranarayanan R, Budukh AM, Rajkumar R. Effective screening programmes for cervical cancer in low- and middle-income developing countries. Bull World Health Organ. 2001; 79: 954-62.

9. Cuzick J, Clavel C, Petry KU, et al. Overview of the European and North American studies on HPV testing in primary cervical cancer screening. Int J Cancer. 2006; 119: 1095-101. doi: 10.1002/ijc. 21955.

10. Alec $M$, Vassilakos $P$. Cervical cancer information. Available at cervical cancer in developing countries. website: $\quad$ http://www.gfmer.ch/ccdc/cervicalcancer.htm. Accessed at 2/3/2017.

11. Elit L, Jimenez W, McAlpine J, et al. Cervical cancer prevention in low-resource settings. J Obstet Gynaecol Can. 2011; 33(3): 272-9.

12. Sankaranarayanan R, Esmy PO, Rajkumar R, et al. Effect of visual screening on cervical cancer incidence and mortality in Tamil Nadu, India: a clusterrandomised trial. Lancet 2007; 370: 398-406. doi: 10.1016/S0140-6736(07)61195-7.

13. Shastri SS, Mittra I, Mishra GA, et al. Effect of VIA screening by primary health workers: randomized controlled study in Mumbai, India. J Natl Cancer Inst 2014; 106: dju009. doi: 10.1093/jnci/dju009.

14. Sankaranarayanan R, Nene BM, Shastri SS, et al. HPV screening for cervical cancer in rural India. N Engl J Med. 2009; 360: 1385-94. doi: 10.1056/NEJMoa0808516.

15. Campos NG, Sharma M, Clark A, et al. Resources required for cervical cancer prevention in low- and middle-income countries. PLoS One. 2016; 11(10): e0164000. doi: 10.1371/journal.pone. 0164000.

16. World Health Organization. WHO guidelines for screening and treatment of precancerous lesions for cervical cancer prevention. Geneva: World Health Organization, 2013.

17. Denny L, Kuhn L, De Souza M, et al. Screen-and-treat approaches for cervical cancer prevention in lowresource settings: a randomized controlled trial. JAMA. 2005; 294: 2173-81. doi: 10.1001/jama.294.17.2173

\section{E-mail: dr.banqasim@yahoo.com}

